Evaluation of Knowledge and Belief on False Reports and Misinformation from Social

ESJ Natural/Life/Medical Sciences

Shehroz Shahid,

Karachi Medical and Dental College

Ramsha Habibullah Mangrio,

Jinnah Postgraduate Medical Centre

\section{Munib Abbas,}

Karachi Medical and Dental College

\section{Zeeshan Ali,}

Jinnah Postgraduate Medical Centre

Masroor Ahmed,

Jinnah Postgraduate Medical Centre

Submitted: 17 August 2020

Accepted: 18 December 2020

Published: 31 December 2020

Corresponding author:

Shehroz Shahid

DOI: $10.19044 /$ esj.2020.v16n36p8

(c)

Copyright 2020 Shahid S,

Distributed under Creative Commons

BY-NC-ND 4.0 OPEN ACCES

Cite as:

Shahid S, Mangrio H. Abbas M., Ali.Z., Ahmed.M. (2020). Evaluation of Knowledge and Belief on False Reports and Misinformation from Social Media in COVID-19 Pandemic: A Web Based Cross-Sectional Survey in Karachi, Pakistan. European Scientific Journal, ESJ, 16 (36), 1. https://doi.org/10.19044/esj.2020.v16n36p8
Media in COVID-19 Pandemic:

A Web Based Cross-Sectional

Survey in Karachi, Pakistan.

\section{Abstract}

COVID-19 has become a global pandemic declared by World Health Organization (WHO) on March 11, 2020. This has put drastic impact on the world and many lives have been affected globally. As the cases of COVID-19 infected are increasing, the spread of fake news related to treatment and its prevention have led to a very difficult situation in controlling and containing the COVID-19 infection. It seems that general public tend to belief in rumors and share them on social media platforms that lead to misinformation which go viral and has created chaos among the general masses. The study evaluated the role of social media in false reporting and spreading misinformation in COVID-19 pandemic. Study also evaluated the knowledge, belief and awareness among general population of the Karachi city to provide insights and to enable ministries and policy makers to take suitable measures. This is a cross sectional study which was conducted from June to July 2020 in Karachi, Pakistan. A self-structured questionnaire was administered through Facebook and Whatsapp due to lockdown and increase risk of exposure from COVID-19 to the research assistants. Data collected was analyzed using descriptive and inferential statistics of frequency counts, and percentages of quantitative variables and Chi square for the inferential variable at 0.05 level of significance. A total of 267 participants were sampled for the study. The study indicates that majority of the participants believed in the myths and false reports circulated on social media and usually share and forward such news 
without authentic references.

Subject: Medical Sciences

Keywords: COVID-19, Social media, Misinformation

\section{Introduction}

In the late December 2019, many cases of pneumonia of unknown origin were reported by China to World Health Organization (WHO) that occurred in the city of Wuhan, Hubei province of China which was later discovered by Chinese scientist to be caused by Coronavirus (Phelan, Katz, \& Gostin, 2020). The WHO has declared COVID-19 as a global pandemic on March 11, 2020 (Djalante et al., 2020). Currently COVID-19 has a huge impact on the world and has affected many lives globally.

The virus has incubation period of about 2 to 14 days (Wu \& McGoogan, 2020). Its clinical features varies from asymptomatic to loss of taste and smell, to moderate symptoms of fever, dry cough, dyspnea, myalgia, fatigue, leukopenia, lymphopenia and radiographic evidence of pneumonia and may worsen to severe disease and lead to Acute Respiratory Distress Syndrome (ARDS), myocarditis, shock and acute kidney injury and death can also occur in severe cases (Bai et al., 2020). Its worldwide fatality rate is $6.73 \%$ while largest rate in Italy was $14.15 \%$ (Roser, Ritchie, Ortiz-Ospina, \& Hasell, 2020).

In the present era, social media has become a considerable source to spread information and awareness but unfortunately, spread of fallacious and deceptive messages is more widespread (Shu, Sliva, Wang, Tang, \& Liu, 2017). Over the past ten years, social media networking became very approachable and popular (Babatunde, 2017). It is observed that the spread of propaganda and fake news make a way to each and every house hold as compared to authentic information. The motto of social media sites on the matter of freedom of speech has led to expeditious and massive sharing without proper verification and there is immense absence of check and balance and quality assurance (Cinelli et al., 2020).

With the passing time, as the cases of COVID-19 infected are increasing geometrically, on the one hand, the spread of fake news related to treatment and its prevention have led to a very difficult situation in controlling and containing the COVID-19 infection (Ali, Hashmi, \& Hussain, 2020). It is observed that general public tend to belief in rumors and share them on social media platforms which lead to the generation of a vicious cycle and spread of the misinformation to a wide area which has created turmoil among the general civilian masses. Such misinformation is not only leading towards xenophobia but it is risking the health of many people and is causing difficulty for 
government to effectively handle and contain the situation (Pulido, VillarejoCarballido, Redondo-Sama, \& Gómez, 2020).

Hence, the study evaluated the knowledge, belief and awareness among general population of the city of Karachi, Pakistan on false reports, misinformation and fake news associated with COVID-19 pandemic. Study also investigated the role of social media applications in spreading news without authentic reference and myths related to the prevention and treatment of COVID-19 infection. The purpose of the study is to provide directions for future researchers to automatize fake news detection system on social media. The study highlight the importance of banning fake social media sites and provide insights to enable ministries and policy makers to take suitable measures.

\section{Methodology}

This is a cross sectional study as it is a population based survey and involves looking data at one specific point in time. The study was conducted from June to July 2020 in Karachi, the largest city of Pakistan with the estimated population of 11,624,219. A non-probability consecutive sampling was used as only those subjects were selected who met the inclusion criteria until required sample size was achieved. Confidence interval 'CI' was estimated using the formula;

$\mathrm{CI}=\mathrm{p} \pm \mathrm{z}_{\mathrm{c}} \sqrt{ } \mathrm{pq} / \mathrm{n} \times \sqrt{\mathrm{N}}-1 / \mathrm{N}-\mathrm{n}$

Where ' $\mathrm{CI}$ ' is Confidence Interval for Finite Population, ' $\mathrm{p}$ ' is population proportion, ' $z$ ' ' is $z$ value, ' $q$ ' is negative probability, ' $n$ ' is the sample size and ' $\mathrm{N}$ ' is the size of population.

Sample size ' $n$ ' was calculated using the formula;

$$
\mathrm{n}=\mathrm{z}_{\mathrm{c}}^{2} \mathrm{p}(1-\mathrm{p}) / \mathrm{ME}^{2}
$$

Where ' $n$ ' is the sample size, ' $p$ ' is population proportion, ' $z_{c}$ ' is $z$ value and 'ME' is the Margin of Error.

With a confidence interval 'CI' of 95\%, population proportion 'p' of $50 \%$, Margin of Error 'ME' 6\% and population size ' $N$ ' of Karachi city, the sample size 'n' calculated was 267.

The eligibility criteria include all individuals with social media account in high school and tertiary institutions and are not less than 18 years of age participated in the study. The participants were selected consecutively.

An instrument was self-structured questionnaire with the satisfactory reliability judged by internal consistency and validity by validity index. The reliability and validity of the instrument made it a useful measure. Questionnaire was circulated via social media platforms including Facebook and Whatsapp due to COVID-19 lockdown and avoidance of its increased risk of exposure to the research assistants. An informed consent was obtained online from each participant before proceeding to the questionnaire. 
Individuals who were not willing to give a conscious consent were exempted to be a part of the study. Participants responded to the instrument with 37 questions which was divided into two sections. Section A comprises the demographic data with 7 questions while section B contains information that investigated the perception of the participants on the false news and role of social media in spreading misinformation regarding COVID-19 pandemic with 30 questions. Section B had close ended questions along with the ones structured in a 1-10 points modified Likert scale.

Online survey was opened for the period of two weeks. $28 \%$ of responses were collected within 2 days, $64 \%$ were collected within the first week and the remaining responses were collected during the second week. Data collected was analyzed using descriptive and inferential statistics. Descriptive data was analyzed using frequency counts and percentages while Statistical Packaging for Social Sciences (SPSS-20) was used to analyze inferential statistics of Chi square at 0.05 level of significance.

\section{Results}

A total of 267 participants were sampled for the study. Table 1 present the demographic data of the participants.

\begin{tabular}{lr} 
Item & $\mathbf{n ~ ( \% )}$ \\
Age in years & \\
$18-25$ years & $108(40.3 \%)$ \\
$26-30$ years & $130(48.5 \%)$ \\
$31-35$ years & $22(8.2 \%)$ \\
$36-40$ years & $2(0.7 \%)$ \\
41 years or older & $3(1.1 \%)$ \\
\hline Gender & \\
Male & $91(34.7 \%)$ \\
Female & $177(65.3 \%)$ \\
\hline Educational status & \\
Post graduate & $95(35.4 \%)$ \\
Graduate & $153(57 \%)$ \\
Higher Secondary Education & $20(7.5 \%)$ \\
\hline
\end{tabular}

Table 1. Demographic characteristics of study participants

In table 1, 130(48.5\%) of the participants were in the age range of 2630years, followed by $108(40.3 \%)$ within the age range of 18-25years, $22(8.2 \%)$ within $31-35$ years of range, $3(1.1 \%)$ were 41 years or older and $2(0.7 \%)$ were in the range of 36-40 years. The participants younger than 18 years of age were excluded from the study. 177(65.3\%) of the participants were women and 91(34.7\%) were man. More than half of the study population; $56 \%$ were qualified up to graduate level of education, $35.1 \%$ were postgraduates while only $9 \%$ were high school graduates (table 1 ). 


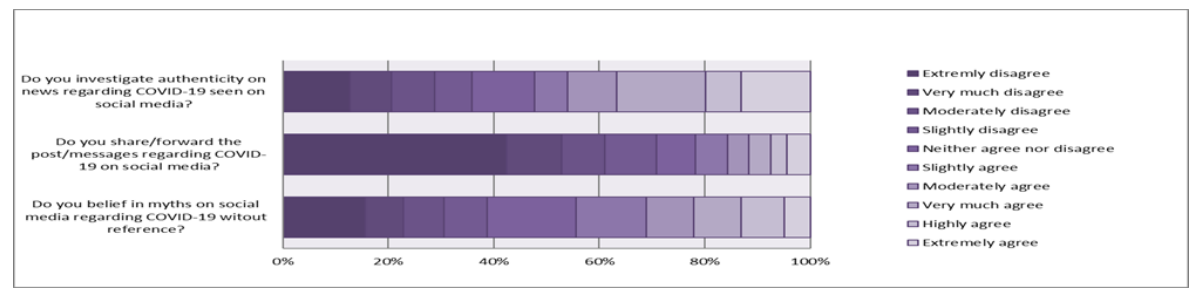

Figure 1. Likert scale showing participant's responses (scored 1-10).

Figure 1 shows 1-10 scored Likert scale with 1 being the lowest or representing 'Extremely disagree' whereas 10 showing the highest or 'Extremely agree' for the response. Study found that some participants were well aware as $16.8 \%$ reported that they investigated the authenticity of news related to COVID-19 pandemic found on social media, $12.7 \%$ usually didn't check the authenticity while $11.9 \%$ were neutral. It was found that $42.5 \%$ of participants didn't share any news or report related to COVID-19 on social media without any reference whereas only $4.5 \%$ frequently share such news. 4.9\% participants expressed their belief on the circulating social media posts without any reference and authentic source, $15.7 \%$ showed extreme disbelief while $16.8 \%$ participants were neutral (Figure 1 ).

Have you seen these myths on social media?

Drinking excess water can prevent Coronavirus
China has bio-engineered the deadly Coronavirus
Self-medication of quinine can prevent Coronavirus
Exposure to hot weather can prevent Coronavirus
Seena makki can treat the symptoms of Coronavirus

Do you belief these facts?

Drinking excess water can prevent Coronavirus infection

China has bio-engineered the deadly Coronavirus

Self-medication of quinine can prevent Coronavirus

Senna makki can treat the symptoms of Coronavirus

Exposure to hot weather can prevent Coronavirus

$\begin{array}{rc}\text { Yes } & \text { No } \\ \mathbf{n ~ ( \% )} & \mathbf{n ~ ( \% )} \\ 196(73.1 \%) & 72(26.9 \%) \\ 214(79.9 \%) & 54(20.1 \%) \\ 196(73.1 \%) & 72(26.9 \%) \\ 216(80.6 \%) & 52(19.4 \%) \\ 215(80.2 \%) & 53(19.8 \%)\end{array}$

Yes

n (\%)

$105(39.2 \%)$

88(32.8\%)

$68(25.4 \%)$

$53(19.8 \%)$

75(28.0\%)
No

n (\%)

$163(60.8 \%)$

$180(67.2 \%)$

200(74.6\%)

215(80.2\%)

193(72.0\%)

Table 2. Circulating myths on social media in COVID-19 pandemic and participant's belief ratio

The study reported about various myths, rumors and false news which were evident on social media sites. 196 (73.1\%) participants have seen the fact of sipping excess water for the prevention of Coronavirus infection and 105(39.2\%) of them believed it to be true. 214(79.9\%) participants have heard the news that China has bio-engineered the deadly Coronavirus while 88(32.8\%) of them actually believed it true. During lockdown, a myth was circulated on social media sites about self-medication of quinine supplements for the treatment of this infection. 196(73.1\%) have read about this on some 
social media sites. However 68(25.4\%) believed it to be true. 216(80.6\%) of participants reported to have seen the myth on social media sites that exposure to hot environment can prevent the spread of Coronavirus. Whereas, $75(28.0 \%)$ of them really believed it true. $215(80.2 \%)$ of participants reported to have seen the fact on social media sites that seena makki can be effective for the symptoms of Coronavirus while, 53(19.8\%) of them considered it to be true (Table 2). Upon querying that on which social media platform they see such myths and false news, majority of participants reported to witness them on Facebook, WhatsApp, Instagram along with Twitter and local blogging sites in decreasing order of statistic (Figure 2).

Further conclusion extracted from the study were about the questions that if they verify the information regarding COVID-19 from an authentic media, whether they share the unauthenticated news with family and friends and an estimation of their reaction on the increasing cases of COVID-19. The results show that $63.4 \%$ of participants reported that they verify the facts and figures about COVID19 pandemic from the official reporting websites. 70.5\% of participants communicated the unverified news and case numbers of COVID-19 infected with others. On Likert scale, less than half of the participants; $45.1 \%$ get highly and extremely worried by noticing the increase figure of COVID-19 infected patients reported and shared on social media sites.

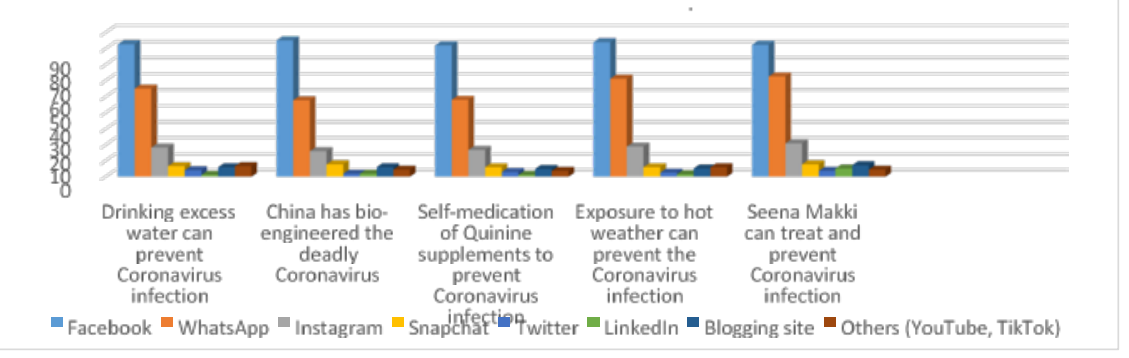

Figure 2. Column bar graph showing participant's responses about social media sites showing the myths

\section{Discussion}

The above mentioned results have adequately shown how social media sites have contributed in propagation of fake knowledge; many of the above mentioned facts were just some myths which were propagated on various social media platforms. Although, the individuals who participated in study were considered to be literate but still a great fraction of them considered these myths to be true. According to the research held in Pak Emirates Military Hospital (PEMH) Rawalpindi, it was shown that many patients were using alternate treatment along with the treatment prescribed by the doctors, since 
there is no scientifically proven medicine so they believed in trying alternate medications (Rana et al., 2020). This research survey revealed that, most popular herbal treatment was found to be seena leaves locally named Seena makki and it was reported that many patients boiled the leaves and used to drink it. Patients believed it to be soothing for their throat and relieving myalgia however, in general practice, seena leaves have strong laxative property and can be used for constipation (Cirillo \& Capasso, 2015).

Drinking of excess water may promote various metabolic activities, it keeps the body hydrated and have many health benefits. However, drinking loads of water does not guarantee the prevention of coronavirus infection, and it was one of the myths to be prevailing among individuals (Arshad et al., 2020). Another greatest myth circulated on social media about quinine supplements that it can be used as self-medication for the treatment Coronavirus infection, while looking at the basic pharmacological background and recent publications, it is hypothesized that Chloroquinone, having antiviral properties can improve the clinical outcome of patients infected by SARSCoV-2 (Devaux, Rolain, Colson, \& Raoult, 2020). However, another study from Oxford academic stated that none of the acute viral infection were successfully treated by Chloroquinone or other quinine derivatives neither did it show any anti-SARS-CoV effect in an in-vivo model (Guastalegname \& Vallone, 2020). Since, the exact pathogenesis of COVID-19 is still a question, immune effects of administration of quinine derivatives in COVID-19 patients cannot be predicted (Cirino \& Ahluwalia, 2020). Furthermore, Chloroquinone is known for its hemolytic effects in patients with Glyceraldehyde-3phosphate Dehydrogenase (G6PD) deficiency tagging it as a drug that shall never be self-medicated (Martins et al., 2015).

False reports and claims are dangerous as these are not only related to the medical aspects of the virus and treatment but have also caused hardship for government to control the situation. A false information that spread in Ireland, US, Germany and France via messages and social media platforms was that of an immediate lockdown at a time when there was no final verdict for lockdown implementation (Kask, 2020). In Estonia, within 24 hours, a single circulated message to a defense organization resulted into an unsure situation of capital lockdown.

The suggestions and information for clinicians which help them respond to the patients false believes is very little (Chou, Oh, \& Klein, 2018). In this regard, communicators of public health should involve to redirect people by disclosing the rumors and by promoting the evidence based reports.

There may be intrinsic variable playing a role in specific demographic settings which affect the graph of awareness and perception of population towards social media false news. A multi country survey in Europe show that one third of population use social media for seeking health related information 
(Redecker, Ala-Mutka, \& Punie, 2010). The COVID-19 pandemic is tending to incline the considerable mental health issues in community (Druss, 2020). A study amongst the U.S population show that people share false claims on social media related to COVID-19 because they fail to realize that content they are spreading is not accurate (Pennycook, McPhetres, Zhang, Lu, \& Rand, 2020). Comprehensively, further research surveys and qualitative work should be conducted in different demographic settings to explore more about the knowledge and belief on false reports, role social media is playing in spreading the misinformation and, sabotage and harm on mental health these fake news are bringing about.

\section{Conclusion}

The study assess the knowledge and belief on false Reports and misinformation in COVID-19 Pandemic and highlight the role of social media in false reporting the figures and facts associated with COVID-19 pandemic. To combat this situation on misguide, it is important to provide awareness in general population about social media usage despite the adequate knowledge being available. The findings from the study can be brought to bear the policies about social media transparency that will be more focused and concerned about public mental health.

\section{References:}

1. Ali, S. M., Hashmi, A., \& Hussain, T. (2020). Causes and treatment of Covid-19: Myths vs Facts. Pakistan Journal of Pharmaceutical Sciences. 33(4).

2. Arshad, M. S., Khan, U., Sadiq, A., Khalid, W., Hussain, M., Yasmeen, A., . . . Rehana, H. (2020). Coronavirus disease (COVID-19) and immunity booster green foods: A mini review. Food Science Nutrition. 8(8), 3971-3976.

3. Babatunde, E. O. (2017). The Influence of Social Media and Environmental Factors on Academic Performance of Student Nurses in South-West Nigeria. European Scientific Journal. 13(10), 295-306.

4. Bai, Y., Yao, L., Wei, T., Tian, F., Jin, D.-Y., Chen, L., \& Wang, M. (2020). Presumed asymptomatic carrier transmission of COVID-19. Jama. 323(14), 1406-1407.

5. Chou, W.-Y. S., Oh, A., \& Klein, W. M. (2018). Addressing health-related misinformation on social media. Jama. 320(23), 2417-2418. 
6. Cinelli, M., Quattrociocchi, W., Galeazzi, A., Valensise, C. M., Brugnoli, E., Schmidt, A. L., . . . Scala, A. (2020). The covid-19 social media infodemic. arXiv preprint arXiv:.05004

7. Cirillo, C., \& Capasso, R. (2015). Constipation and botanical medicines: an overview. Phytotherapy Research. 29(10), 14881493.

8. Cirino, G., \& Ahluwalia, A. (2020). The many mechanisms of action of Chloroquine: to use or not to use (in COVID-19) that is the question. British Journal of Pharmacology. 177(15), 3361.

9. Devaux, C. A., Rolain, J.-M., Colson, P., \& Raoult, D. (2020). New insights on the antiviral effects of chloroquine against coronavirus: what to expect for COVID-19? International journal of antimicrobial agents. 105938.

10. Djalante, R., Lassa, J., Setiamarga, D., Mahfud, C., Sudjatma, A., Indrawan, M., . . . Djalante, S. (2020). Review and analysis of current responses to COVID-19 in Indonesia: Period of January to March 2020. Progress in Disaster Science. 100091.

11. Druss, B. G. (2020). Addressing the COVID-19 pandemic in populations with serious mental illness. JAMA psychiatry

12. Guastalegname, M., \& Vallone, A. (2020). Could chloroquine/hydroxychloroquine be harmful in coronavirus disease 2019 (COVID-19) treatment? Clinical Infectious Diseases.

13. Kask, M. (2020). False information about coronavirus and beyond: Lessons for the EU?

14. Martins, A. C., Cayotopa, A. D. E., Klein, W. W., Schlosser, A. R., Silva, A. F. d., Souza, M. N. d., . . d da Silva-Nunes, M. (2015). Side effects of chloroquine and primaquine and symptom reduction in malaria endemic area (Mâncio Lima, Acre, Brazil). Interdisciplinary perspectives on infectious diseases. 2015.

15. Pennycook, G., McPhetres, J., Zhang, Y., Lu, J. G., \& Rand, D. G. (2020). Fighting COVID-19 misinformation on social media: Experimental evidence for a scalable accuracy-nudge intervention. Psychological science. 31(7), 770-780.

16. Phelan, A. L., Katz, R., \& Gostin, L. O. (2020). The novel coronavirus originating in Wuhan, China: challenges for global health governance. Jama. 323(8), 709-710.

17. Pulido, C. M., Villarejo-Carballido, B., Redondo-Sama, G., \& Gómez, A. (2020). COVID-19 infodemic: More retweets for science-based information on coronavirus than for false information. International Sociology. 0268580920914755.

18. Rana, M. J., Qureshi, A. A., Amanullah, A., Khan, N. U. S., Shafqat, H., \& Khalil, A. A. (2020). SURVIVING COVID-19: AN 
ILLNESS NARRATIVE OF PATIENTS IN PAKISTAN. Pakistan Armed Forces Medical Journal. 70(1), S212-219.

19. Redecker, C., Ala-Mutka, K., \& Punie, Y. (2010). Learning 2.0: The impact of social media on learning in Europe. Policy brief. JRC Scientific Technical Report.

20. Roser, M., Ritchie, H., Ortiz-Ospina, E., \& Hasell, J. (2020). Coronavirus pandemic (COVID-19). Our World in Data

21. Shu, K., Sliva, A., Wang, S., Tang, J., \& Liu, H. (2017). Fake news detection on social media: A data mining perspective. ACM SIGKDD explorations newsletter. 19(1), 22-36. 